\title{
Oferta de Parques Urbanos e Naturais em Sorocaba (SP): alavanca para políticas de uso público
}

\section{Urban and Natural Parks supply in Sorocaba (SP, Brazil): encouragement for public use polices}

\author{
Kleber Vinícius Barros Kachinsk, Maria Helena Mattos Barbosa dos Santos, \\ Eliana Cardoso-Leite
}

RESUMO: Conservar a natureza e garantir o uso pelas populações é elemento central na construção dos programas de uso público dos parques urbanos e naturais municipais, tendo em vista a relevância que os temas vinculados ao meio ambiente, assumem em nossa sociedade, sobretudo, em interface com valores e práticas imbricadas na estrutura social, econômica e política vigente. No que diz respeito ao desenvolvimento da consciência e de práticas de conservação ambiental, é fundamental considerar as características locais e, ao mesmo tempo, não apenas garantir o acesso a programas de educação não formal e de uso público de espaços coletivos e públicos, mas também fomentar práticas culturais e lazer nestes espaços. Isto porque, inclusive, os espaços públicos e seus usos implicados, considerando os apontamentos de Jacobs (2011), são fundamentais para as cidades mais vivas, seguras, sustentáveis e saudáveis. O presente trabalho aborda os parques em ambiente urbano, buscando analisar a distribuição destas áreas na cidade de Sorocaba e como se dá o uso do espaço público pela população, por meio de práticas recreativas e de lazer. O estudo de caráter exploratório, descritivo, pautado em abordagem quali-quanti, foi realizado por meio da combinação da pesquisa bibliográfica, documental e da pesquisa de campo, balizada por observação sistemática (suportada por protocolo de observação) e realização de entrevistas semiestruturadas, com os usuários dos parques urbanos e parques naturais municipais do município de Sorocaba. Estas pesquisas foram realizadas na área amostral de 8 parques da cidade (4 delimitados - cercados e 4 sem delimitação física - não cercados) e os resultados apontam que há disparidades na oferta de serviços com relação à política de atividades e ao quesito segurança, bem como recorrente demanda por melhorias da infraestrutura e paisagismo ambiental. Os parques de Sorocaba, são utilizados para a prática de esportes, para o descanso, encontro com amigos, passeios com crianças e contemplação da natureza. Entretanto, apesar do elevado número de parques criados e de sua distribuição atender a todas as regiões de Sorocaba, estes resultados suportam ações para uma intervenção mais assertiva das instituições do setor público, no que se refere à devida valorização da importância das atividades de cultura e lazer, inclusive àquelas destinadas ao fomento da preservação e conservação ambiental - via práticas de educação ambiental - em todas as regiões, que forçosamente resultarão em melhorias dos aspectos paisagísticos, da manutenção e conservação e dos resultados, inestimáveis, de maior segurança pública.

PALAVRAS-CHAVE: Parques Urbanos; Uso Público; Lazer; Meio Ambiente; Sorocaba-Brasil. 


\section{ABSTRACT}

Conserving nature and guaranteeing its use by the population is a central element in the construction of programs for the public use of urban parks, in view of the relevance that the themes related to the environment assume in our society, above all, interfacing with articulation values and practices in the current social, economic and political structure. Concerning the development of environmental awareness and conservation practices, it is essential to consider local characteristics and, at the same time, not only guarantee access to non-formal education programs and public use of collective and public spaces, but also promote cultural practices and leisure in these spaces. This is because public spaces and their uses, considering the Jacobs (2011) notes, are fundamental for cities that are more alive, safe, sustainable and healthy. he present work deals with the parks in an urban environment, trying to analyze the distribution of these areas in the city of Sorocaba and how the public space is used by the population, through recreational and leisure practices. The exploratory, descriptive study, based on a quali-quanti approach, was carried out through a combination of bibliographic, documentary and field research, using systematic observation (supported by observation protocol) and semi-structured interviews with users of urban parks and natural parks in the municipality of Sorocaba. These surveys were carried out in the sample area of 8 city parks (4 delimited - fenced and 4 without physical delimitation - not fenced) and the results indicate that there are disparities in the service offer in relation to the activities policy and the safety question, as well as environmental and landscape improvements. The parks of Sorocaba, are used for sports, for rest, meeting with friends, walks with children and contemplation of nature. However, despite the high number of parks created and their distributions serving all regions of Sorocaba, these results support actions for a more assertive intervention of public sector institutions, regarding the proper appreciation of the importance of culture and leisure activities , including those aimed at promoting environmental preservation and conservation - via environmental education practices - in all regions, which will inevitably result in improvements in the landscape, maintenance and conservation, and invaluable results of greater public safety.

KEYWORDS: Urban Parks; Public Use; Leisure; Environment; Sorocaba-Brazil.

\section{Introdução}

No Brasil e no mundo a temática ambiental tem cada vez mais se destacado, devido a sua importância para a qualidade de vida da população humana, e devido a sua relação com outras esferas de atuação e interesse humano, como as questões econômicas, sociais e políticas, sofrendo influências da estrutura social, econômica e política e, outrossim, estruturando os caminhos de desenvolvimento social. Segundo Rodrigues (2005, p. 3), "os problemas ambientais, do meio ambiente são reais e debatidos desde 0 século XVIII. Tornam-se mais conhecidos na segunda metade do século XX".

Para Vilarta e Gonçalves (2004), a natureza e o lazer são elementos que se fazem presentes à qualidade de vida; no entanto, estes elementos não estão livres das referências históricas, culturais e das estratificações sociais ou de classes de uma sociedade. É importante destacar que o entendimento de meio ambiente e lazer colocados ao longo deste trabalho, refletem esferas de atuação humana, que contribuem para efetivo desenvolvimento dos indivíduos (GUTIERREZ, 1998; STOPPA, 2005). 
Segundo Londe e Mendes (2014), é importante trazer à superfície a discussão a respeito dos benefícios proporcionados por áreas verdes (naturais) à conservação do meio ambiente e à população, que vive, sobretudo, concentrada em ambientes urbanos. A oferta de áreas livres verdes e parques urbanos caracterizam-se como espaços fundamentais para a vida em sociedade, contribuindo, segundo Dantas (2016), para a qualidade ambiental e qualidade de vida da população.

Estas áreas, considerando os resultados de pesquisas empreendidas por Londe e Mendes (2014) e Ferreira (2005), podem desempenhar papel estético (pode-se considerar o que se refere ao belo, formoso), ofertar serviços de caráter ecológico-ambiental (capacidade de redução dos materiais tóxicos, controle climático etc.), consubstanciar práticas de lazer (ao descanso, ócio ou passatempo) e, inequivocamente, estimular a dinamização da economia urbana, em especial as atividades ligadas ao lazer (LONDE E MENDES, 2014).

A partir deste cenário econômico nos núcleos urbanos, os aspectos sociais, políticos e ambientais, sofrem a influência do forte e acelerado crescimento das cidades (JACOBI, 2005). Neste sentido, para Jacobs (2011), as cidades podem e devem fomentar o convívio em espaços públicos, propor lugares qualificados, e viabilizar a satisfação das demandas e necessidades da coletividade (LEFEBVRE, 2011). Ademais, entende-se que os espaços públicos são fundamentais para as cidades mais vivas, seguras, sustentáveis e saudáveis (GEHL, 2013).

Considerando-se que a partir dos anos 1970 grande parte da população brasileira vive em áreas urbanas, o consequente crescimento das cidades mostrou como a ação humana pode alterar os espaços e as paisagens (LIMA; AMORIM, 2006). Neste sentido, a demanda por infraestrutura (água, luz, esgotamento), moradia, transporte, trabalho, saúde educação e lazer transformam negativamente os espaços previamente existentes e criam novos espaços insalubres e com baixa qualidade biótica, física e para uso social.

Neste contexto, Rolnik (2000) argumenta que a compreensão dos aspectos espaciais, compreendidos por ruas, avenidas, praças e parques hoje segregados e fragmentados, é fundamental para a interpretação do lazer no meio urbano. Atualmente, praças e parques estão, em diferentes lugares, condenados ao esquecimento e destinados apenas para vias de circulação.

$\mathrm{O}$ acelerado crescimento das cidades contribuiu para a segregação e fragmentação dos espaços públicos e limitou o acesso e o uso quantitativo e qualitativo da produção cultural e ao lazer, privilegiando determinados grupos sociais em detrimento de outros (ROLNIK, 2000).

Portanto, verifica-se que é importante planejar e criar parques urbanos e parques naturais municipais, além de implantar programas de Uso Público, com vistas não apenas à correção da carência de espaços públicos naturais, mas também, à democratização do uso e apropriação da população de espaços coletivos e da cidade (JACOBS, 2011; LONDE; MENDES, 2014). 
No Brasil, a Constituição Federal de 1988 constitui como um instrumento político determinante para defesa destes direitos sociais e ambientais. Com a nova Constituição, o lazer e o meio ambiente equilibrado são reconhecidos como direitos dos cidadãos, pois estabelece-se no Capítulo $\mathrm{VI}$, do Art. 225, que: "Todos têm direito ao meio ambiente ecologicamente equilibrado, bem de uso comum do povo e essencial à sadia qualidade de vida, impondo-se ao Poder Público e à coletividade o dever de defendê-lo e preservá-lo para as presentes e futuras gerações" (BRASIL, 1988).

Dentro deste contexto, para Munhoz (2008, p. 64) "[...] os direitos sociais visam reduzir os excessos de desigualdades gerados pelo mercado, garantindo um mínimo de bem-estar para os indivíduos". Cavalcanti (2012), por sua vez, contextualiza que, na atualidade, o crescimento econômico é sinônimo de insustentabilidade e que a inversão deste quadro está intimamente associada ao desenvolvimento ambiental e humano possibilitados pelos resultados positivos das atividades econômicas, mas também pela fruição da natureza e do meio ambiente, , contextos nos quais, seus elementos constitutivos e as dinâmicas aí florescidas, garantem a valorização e defesa dos direitos sociais .

Para uma efetiva defesa destes direitos faz-se necessário, também, a formulação, implementação e gestão de políticas públicas de lazer e de outras políticas setoriais que, perseguindo fins particulares e objetivos em comum, fomentem igualmente vivências recreativas e de lazer (GUTIERREZ, 1998; MUNHOZ, 2008).

Neste contexto, Marcellino (2008) aborda que há barreiras inter e intraclasses sociais, que são aspectos importantes a serem compreendidos, pois se relaciona diretamente com o uso, apropriação, democratização dos espaços e equipamentos e ao acesso ao lazer nas cidades.

Em linhas gerais, pode-se apontar a existência de problemas como a carência de áreas verdes urbanas e de áreas protegidas, e a falta de equipamentos específicos destinados a utilização recreativa nestas áreas. Os espaços naturais, parques urbanos e parques naturais municipais, são áreas fundamentais para uma melhoria da qualidade de vida da população que, por meio do lazer, podem ser utilizados para atividades recreativas, lúdicas e contemplativas (PACHECO; RAIMUNDO, 2014).

Seguindo esta dinâmica nacional de crescimento econômico das zonas urbanizadas, a cidade de Sorocaba e a região metropolitana na qual a cidade está inserida sofrem acelerada expansão da sua atividade industrial e de sua zona urbana. A cidade que segundo Priore (2016), desde o ciclo do tropeirismo, é marcadamente complexa de tendências desenvolvimentistas passou por um acelerado desenvolvimento ao longo das últimas décadas com a vinda de muitas indústrias multinacionais, universidades e empresas prestadoras de serviços. Todo este elevado potencial econômico estimulou o crescimento da sua população e consequentemente da sua área urbana, alterando e refletindo nas áreas verdes da cidade.

Mello (2016) estudando áreas prioritárias para conservação mapeou todos os fragmentos florestais do município de Sorocaba, e registrou a 
ocorrência de 2537 fragmentos, sendo $67 \%$ deles de tamanho igual ou menor que 1 ha. Segundo a autora (MELLO, 2016) os maiores fragmentos não estão localizados em áreas públicas. Este estudo também destacou a necessidade de restauração da vegetação nativa das margens dos cursos d'água e ao redor das nascentes.

Motta (2016) analisou as áreas denominadas parques (áreas livres e áreas protegidas) também em Sorocaba. O autor registrou a ocorrência de 33 áreas, sendo que 5 foram consideradas como Unidades de Conservação, 9 como áreas de transição, denominadas pelo autor de AIAs (áreas de interesse ambiental), e 19 foram identificadas como ELUPIS (espaços livres de uso público e interesse social). $\mathrm{O}$ autor conclui que Sorocaba apresenta espaços livres para uso da população, no entanto, a maioria destes espaços não cumpre o papel de conservação dos recursos naturais, sendo mais utilizados para lazer e recreação.

Portanto, a cidade de Sorocaba tem oferta de áreas verdes em seu território e estas são importantes para a qualidade de vida da população (LONDE; MENDES, 2014), além de a cidade gozar de boa condição econômica para investimentos em ações e políticas públicas. A Figura 1 representa o mapeamento dos parques em Sorocaba com destaque em amarelo para os parques abordados neste trabalho.

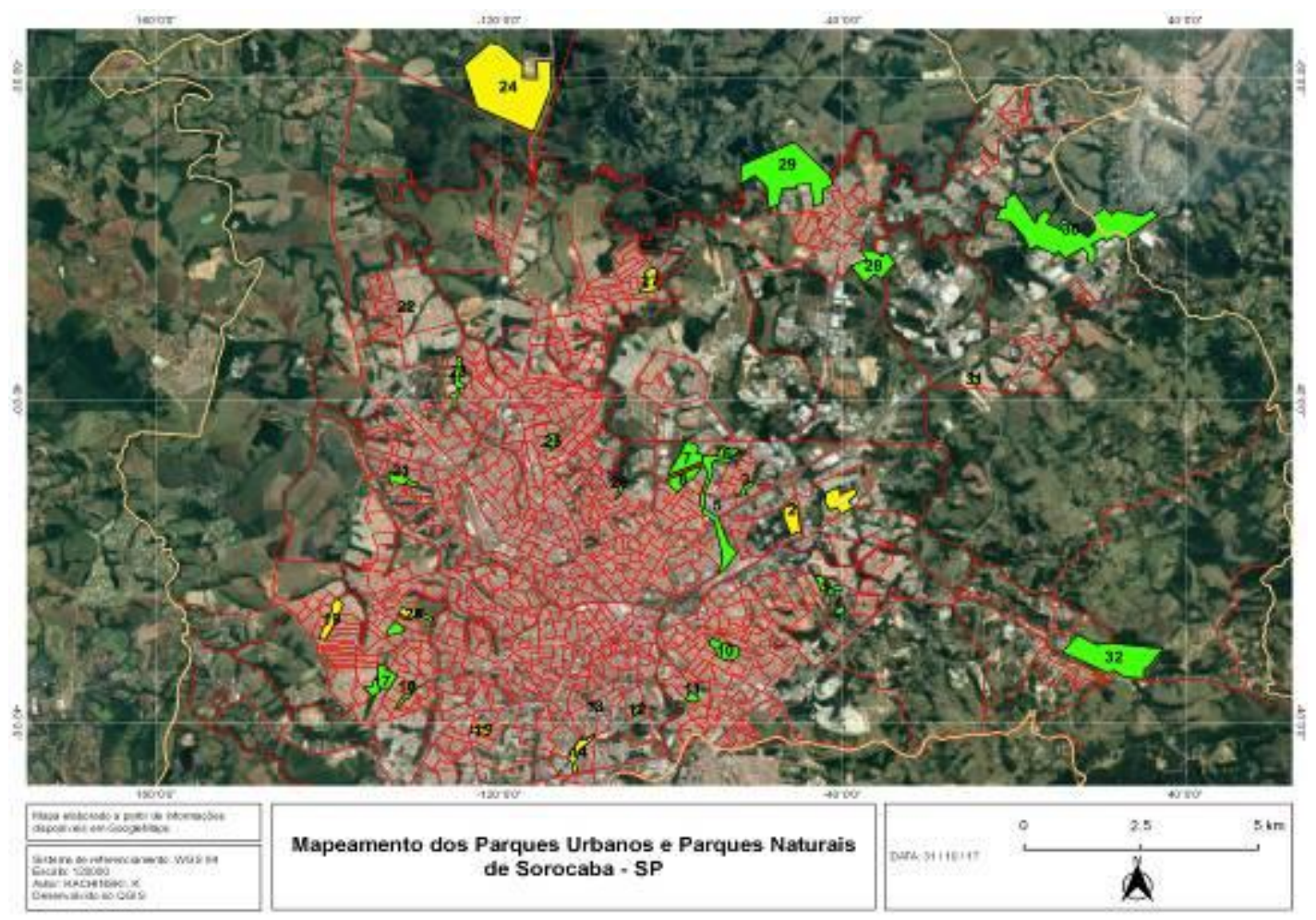

Figura 1: Mapeamento dos Parques Urbanos, e Parques Naturais Municipais de Sorocaba/SP, 2017. Áreas em amarelos foram as áreas amostradas no presente estudo.

Organização: Kachinski (2016). Dados cartográficos 2016 - Google Imagens.

Figure 1: Mapping of Urban Parks and Natural Parks of Sorocaba / SP, 2017. Yellow areas were they studied in this paper

Organization: Kachinski (2016). Map data 2016 - Google Images. 
Assim, o presente trabalho traz como proposta, avançar nos estudos sobre os parques urbanos e parques naturais municipais de Sorocaba e o uso público destes espaços pela sociedade. As perguntas que norteiam este estudo são: Existem parques urbanos e ou parques naturais municipais em todas as regiões de Sorocaba? Os parques são igualmente equipados e conservados, pelo poder público? A população se apropria destes espaços para lazer e recreação? Há programas de Uso Público referente a estas áreas no município?

O estudo de caráter exploratório, descritivo, pautado em abordagem quali-quanti, foi realizado por meio da combinação da pesquisa bibliográfica, documental e da pesquisa de campo, balizada por observação sistemática, (suportada por protocolo de observação) nos parques urbanos e parques naturais municipais do município de Sorocaba. Foram consultados dados da Prefeitura Municipal de Sorocaba através Área de Serviços Urbanos - Divisão de parques - que propiciou a identificação dos parques existentes e suas características.

A análise da distribuição espacial dos PU (Parques Urbanos) e PNM (Parques Naturais Municipais) dentro do município foi realizada mediante a localização das áreas de estudo utilizando-se a ferramenta Google Maps, análise primária cruzada com dados de localização de análises realizadas por Reis (2015), que também contemplaram o estudo da densidade populacional (Figura 2) e renda per capta (Figura 3 ) das diferentes regiões da cidade de Sorocaba (SP).

As áreas estudadas foram selecionadas, a partir do conjunto de parques existentes (Tabela 1), seguindo os critérios físicos e ambientais (tamanho, cobertura vegetal), de acesso ao público (com ou sem cerca) e de localização (distribuídas nas diferentes regiões da cidade). Sendo assim, foram selecionados dois grupos de áreas: um representado por áreas com maior cobertura vegetal (com características relevantes para conservação), e outro grupo representado por áreas delimitadas (cercadas), ambos os grupos com áreas presentes em diferentes regiões da cidade.

Considerando o grupo de áreas com maior cobertura vegetal, foram selecionados: (1) Parque Chico Mendes (Leste), (20) Parque Ouro Fino (Oeste), (15) Parque da Água Vermelha (Sul) e (24) PNM Corredores Da Biodiversidade (Norte). Outrossim, no que se refere ao segundo grupo, composto por áreas com características de parques urbanos (com características relevantes para lazer, recreação e eventos), com menor cobertura vegetal e áreas sem delimitação física (não cercadas). Foram selecionados: (14) Parque Campolim (Sul), (2) Parque do Paço Municipal (Leste), (19) Parque Santa Barbara (Oeste) e (27) Parque Vitória Régia (Norte).

Foram realizadas diversas visitas aos parques, em um primeiro momento de forma exploratória e, posteriormente, com o propósito de observação sistemática, mediante o uso de um roteiro de observação. As primeiras visitas compreenderam a realização de uma caminhada por todo o espaço do parque, a fim de anotar os aspectos gerais do espaço. Os critérios de observação do espaço público foram determinados a partir das análises de 
Gehl e Svarre (2013), além de protocolo de observação desenvolvimento por Pacheco e Raimundo ${ }^{1}$ e comportaram as seguintes categorias e variáveis: Descrição sumária; Estado conservação de equipamentos e limpeza; Relevância cultural; Aspectos socioeconômicos; Registro Fotográfico.

\section{Sorocaba: oferta de Parques Urbanos e Parques Naturais}

A cidade Sorocaba, localizada a oeste do estado de São Paulo, a 90 $\mathrm{km}$ da capital paulista, com uma população acima de 600.000 habitantes (IBGE, 2010), tem um dos maiores Indice de Desenvolvimento Humano (IDH) do Brasil, com 0,798.

A região metropolitana de Sorocaba ${ }^{2}$ conta com aproximadamente 2 milhões de pessoas e é responsável por $3 \%$ do Produto Interno Bruto Estadual (PIB), que em termos totais corresponde à 77, 4 bilhões em dados averiguados pela Fundação Sistema Estadual de Análise de Dados (SEAD, 2016). Sorocaba é responsável por quase $50 \%$ do PIB produzido dentro desta metrópole com uma receita de $\mathrm{R} \$ 30,5$ bilhões, 9o no ranking estadual de receitas produzidas, resultados que, alicerçados no desenvolvimento da indústria, do comércio e dos serviços (há mais 22 mil empresas instaladas) e na exportação de sua produção industrial para mais de 120 países, alçam a cidade à posição de $5^{\text {a }}$ cidade em desenvolvimento econômico do Estado de São Paulo (SEAD, 2015).

Devido ao intenso uso do território e dos elementos ambientais, a cobertura vegetal do município de Sorocaba encontra-se reduzida e distribuída em pontos isolados, com um forte desmatamento do centro para as regiões periféricas, com poucas regiões conservadas de mata. De acordo com o PMMA (2014), o município de Sorocaba possui um total de 45.007,85 ha, dos quais $7.509,02$ de cobertura remanescente de vegetação natural, que representa $16,68 \%$ do território, composta por Floresta Estacional Semidecidual (38.306 ha), Contatos (327.757 ha), Floresta Ombrófila Densa (216.295 ha), Floresta Ombrófila Mista (71.997 ha), Vegetação Ciliar (13.766 ha) e Savanas (16.32 ha).

De acordo com a Área de Serviços Urbanos (ASU), de acordo com dados da Divisão de Parques (DPAR) da Secretaria do Meio Ambiente (SEMA), estão catalogados 33 espaços verdes públicos do município de Sorocaba sob a denominação de parques, conforme a legislação municipal. Deste montante, 25 foram instituídos após a criação do SNUC, no ano 2000 e, entre as unidades de conservação (UC) sorocabanas estão a Estação Ecológica "Governador Mário Covas", localizada no Cajuru; a Estação Ecológica do Pirajibu e o Parque Natural Municipal de Brigadeiro Tobias, criados em 2015, bem como o Parque Natural Municipal Corredores de Biodiversidade, inaugurado em 2013 (MANFREDINI; GUANDIQUE E ROSA, 2015).

A Tabela 1 demonstra as informações do local, região e tamanho dos 33 parques catalogados pela Secretaria de Meio Ambiente de Sorocaba. 
Tabela 1: Localização por região, bairro e tamanho dos Parques da cidade de Sorocaba/SP. As áreas com * são UCs reconhecidas pelo SNUC.

Table 1: Location by region, neighborhood and size of the Parks of the city of Sorocaba / SP. Areas with * are UCs recognized by the SNUC.

\begin{tabular}{|c|c|c|c|c|}
\hline LEGENDA & Nome do Parque & BAIRRO & $\begin{array}{l}\text { ÁREA } \\
(\text { (ha) })^{\star *}\end{array}$ & ZONA \\
\hline 1 & Parque Chico Mendes & Alto da Boa Vista & 14,50 & LESTE \\
\hline 2 & Parque do Paço Municipal de Sorocaba & Alto da Boa Vista & 21,80 & LESTE \\
\hline 3 & Parque Yves Ota & $\begin{array}{l}\text { Jd. Iguatemi/Vila } \\
\text { Morumbi }\end{array}$ & & LESTE \\
\hline 4 & Parque Steve Paul Jobs & Jd. Bandeirantes & & LESTE \\
\hline 5 & Parque Linear Armando Pannunzio - Av. Dom Aguirre. & Abaeté & 25,00 & LESTE \\
\hline 6 & Jardim Botânico de Sorocaba Irmãos Villas - Bôas & Jd. Dois Corações & 19,20 & LESTE \\
\hline 7 & Parque Porto das Águas & Jardim Iguatemi & & LESTE \\
\hline 8 & Parque Das Águas & Jd. Abaeté & 16,20 & LESTE \\
\hline 9 & Parque Dr. Bráulio Guedes da Silva & Além Linha & 8,87 & LESTE \\
\hline 10 & Parque Quinzinho de Barros Zoológico & VI. Hortência & 12,87 & LESTE \\
\hline 11 & Parque dos Espanhóis & Parada do Alto & 2,00 & SUL \\
\hline 12 & Parque da Biquinha & Emília & 2,77 & SUL \\
\hline 13 & Parque Kasato Maru & Campolim & 0,90 & SUL \\
\hline 14 & Parque Campolim & Campolim & 7,40 & SUL \\
\hline 15 & Parque da Água Vermelha & Jd. Europa & 2,70 & SUL \\
\hline 17 & Parque João Pellegrini & Central Parque & 1,73 & OESTE \\
\hline 18 & Parque Antônio Latorre & Jd. Arco Iris & 4,40 & OESTE \\
\hline 19 & Parque Maestro Nílson Lombardi & Jd. Ipiranga & 6,20 & OESTE \\
\hline 20 & Parque Santa Bárbara & $\begin{array}{l}\text { CH. Júlio de } \\
\text { Mesquita Filho }\end{array}$ & 17,30 & OESTE \\
\hline 21 & Parque Ouro Fino & Pq. Ouro Fino & 9,68 & OESTE \\
\hline 22 & Parque Walter Grillo & Lopes de Oliveira & 1,53 & OESTE \\
\hline 23 & Parque - Sist. Lazer Amália Helena Bertelle Camargo & Pq. São Bento & 1,30 & NORTE \\
\hline 24 & Parque Santi Pegoretti & Jd. Maria Eugênia & 8,93 & NORTE \\
\hline 25 & $\begin{array}{l}\text { Parque Natural Municipal Corredores da } \\
\text { Biodiversidade }\end{array}$ & Itavuvú & 7,70 & NORTE \\
\hline 26 & Parque da Formosa & VI. Formosa & 20,00 & NORTE \\
\hline 27 & Parque Ant. Amaro Mendes & Brasilândia & & NORTE \\
\hline 28 & Parque Amedeo Franciulli - Vitória Régia & Pq. Vitória Régia & 24,00 & NORTE \\
\hline 29 & $\begin{array}{c}\text { Parque Rubens Cernomoret - Est. Tratamento de } \\
\text { Água ETA Éden }\end{array}$ & Éden & 1,30 & NORTE \\
\hline 30 & Parque Natural Municipal Pirajibu* & Éden & 45,00 & NORTE \\
\hline 31 & Estação Ecológica Governador Mário Covas* & Cajurú & 50,07 & NORTE \\
\hline 32 & Sist. De Lazer - Parque Raul de Moura Bittencourt & Villa Amato & & LESTE \\
\hline 33 & Parque Natural Municipal de Brigadeiro Tobias* & Passa Três & 1,56 & LESTE \\
\hline
\end{tabular}


Pode-se observar que existe oferta de PU em todas as regiões da cidade, e de PNM apenas nas regiões norte e leste (Figura 1). O total da soma da extensão territorial dos parques de Sorocaba compreende uma área de 374,7 ha, sendo que o parque com menor área, denominado Parque Margarida Leão Camargo - possui uma área de 0,6711 ha e o maior, a Unidade de Conservação "Governador Mário Covas", na zona norte, compreende uma área de 50,07 ha.

Destes parques, 4 são Unidades de Conservação (UC), ou seja, estão incorporados ao Sistema Nacional de Unidades de Conservação da Natureza (SNUC) e à Lei 11.073 que instituiu o Sistema Municipal de Áreas Protegidas, Parques e Espaços Livres de Uso Público. O Parque Natural Municipal Corredores da Biodiversidade e Parque Natural Municipal Pirajibu, e a Estação Ecológica Mário Covas, localizados na zona norte, são UCs, assim como Parque Natural Municipal de Brigadeiro Tobias, instalado na zona leste.

As duas regiões que mais possuem metros quadrados ou hectares em parques são a região leste, que possui 12 parques, totalizando 120,01 ha, dos quais 1 é $U C$, e a região norte, que possui 6 parques urbanos e 3 parques naturais municipais (UCs Gov. Mario Covas, Corredores da Biodiversidade e Pirajibu) que são prioritárias para preservação e conservação da natureza. Estas 9 áreas totalizam 158,30 ha e apresenta-se como relevante na questão da conservação de áreas naturais, pois apresenta as maiores concentrações de domicílios particulares permanentes e atendem a uma grande concentração de pessoas (Figura 2). Já a zona sul, dispõe de 5 parques; é a região com menor número de parques, que totalizam 15,77 ha. A zona oeste, por fim, possui 6 parques, totalizando 40,05 ha em área.

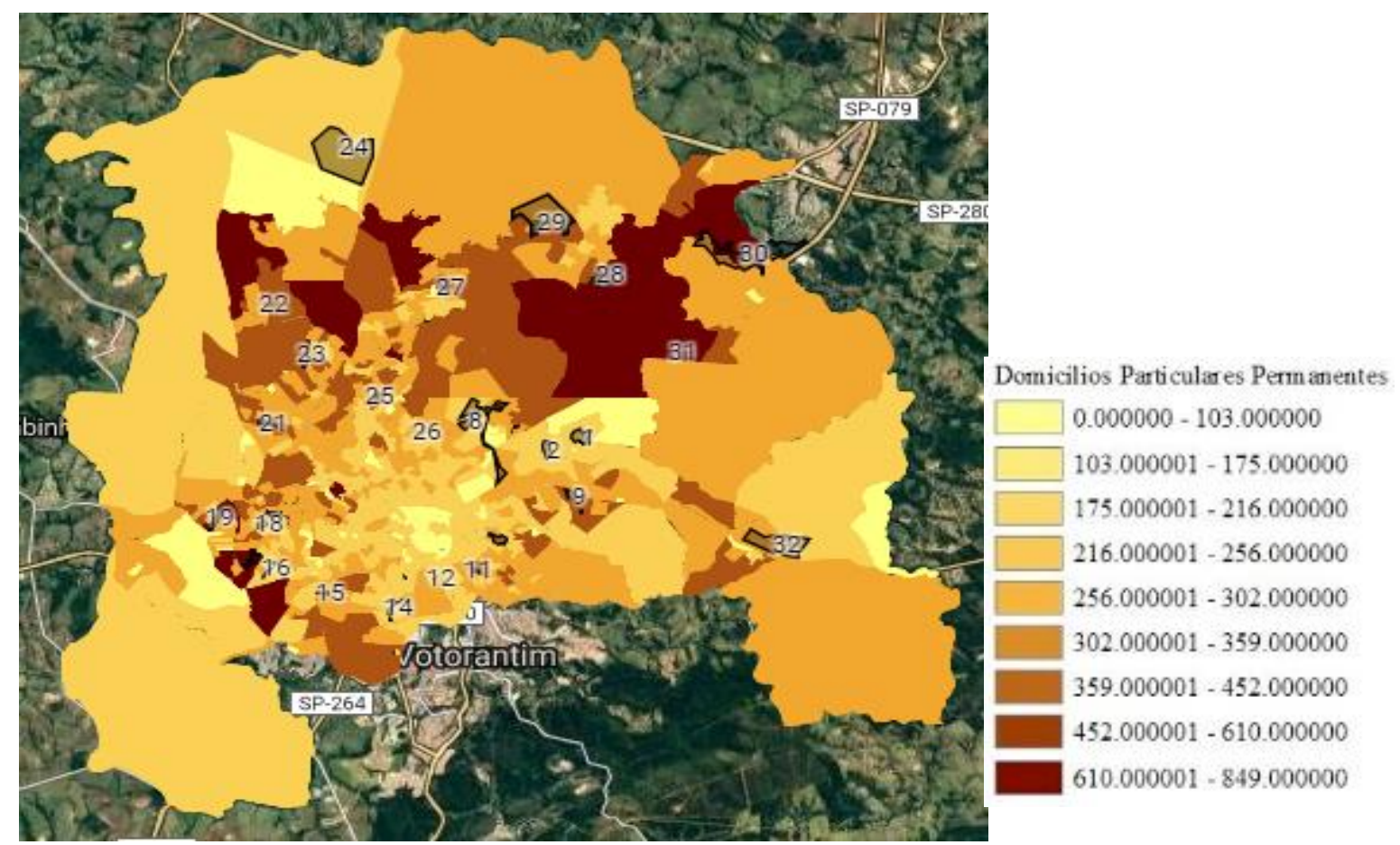

Figura 2: Distribuição espacial dos domicílios de Sorocaba e Mapeamento dos Parques em (ha).

Organização: Kachinski (2017). Dados cartográficos 2016 - Google Imagens e Dados do IBGE (2010).

Figure 2: Spatial distribution of Sorocaba households and Park Mapping in (ha).

Organization: Kachinski (2017). Map data 2016 - Google Images and IBGE data (2010). 
Analisando a relação entre a distribuição de parques e a distribuição de renda do município (Figura 3), pode-se observar que as maiores rendas estão nas regiões sul e leste, porém a distribuição dos parques se dá em toda extensão de área do município, estando ausente apenas na região central da cidade.

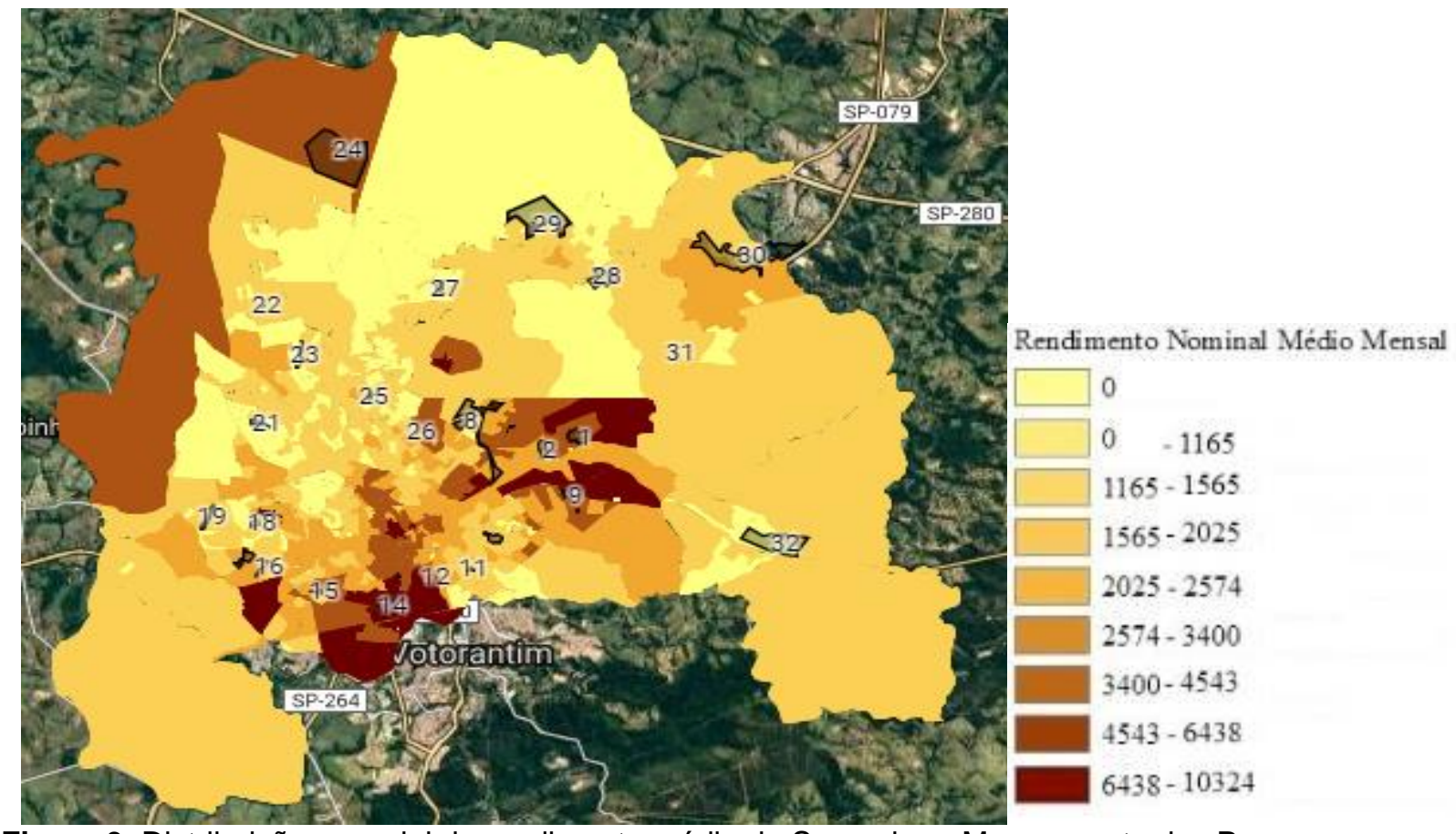

Figura 3: Distribuição espacial do rendimento médio de Sorocaba e Mapeamento dos Parques. Organização: Kachinski (2017). Dados cartográficos 2016 - Google imagens e Dados do IBGE (2010).

Figure 3: Spatial distribution of Sorocaba mean yield and Park Mapping.

Organization: Kachinski (2017). Map data 2016 - Google images and IBGE data (2010).

No entanto, alguns parques das zonas sul e leste mostram-se mais visitados, o que pode indicar uma relação entre maior poder aquisitivo (renda) e hábito de frequentar parques ou, ainda, que estas áreas estejam mais bem estruturadas que aquelas das zonas oeste e norte.

Em relação à política e gestão de parques urbanos, Sorocaba pode ser comparada com outras cidades como Juiz de Fora em Minas Gerais (PAULA E FERREIRA, 2014). Sorocaba conta com uma maior distribuição dos parques no espaço urbano da cidade, em relação a Juiz de Fora e, em ambas as cidades, os parques com melhor infraestrutura e bem equipados ficam em regiões de maior renda.

\section{O Uso Público nos Parques Urbanos e Parques Naturais em Sorocaba}

Neste contexto, os dados apresentados a seguir buscam contribuir com respostas ao entendimento sobre a frequência de visitantes aos parques, bem como os usos realizados nestes locais. Para tanto, fez-se necessário verificar também os contextos existentes, que estão para além do equipamento, 
contando com a análise do entorno imediato (Tabela 2) de cada objeto de estudo.

Tabela 2: Protocolo de observação do Espaço Urbano - Entorno imediato.

Table 2: Protocol of observation of the Urban Space - Immediate environment.

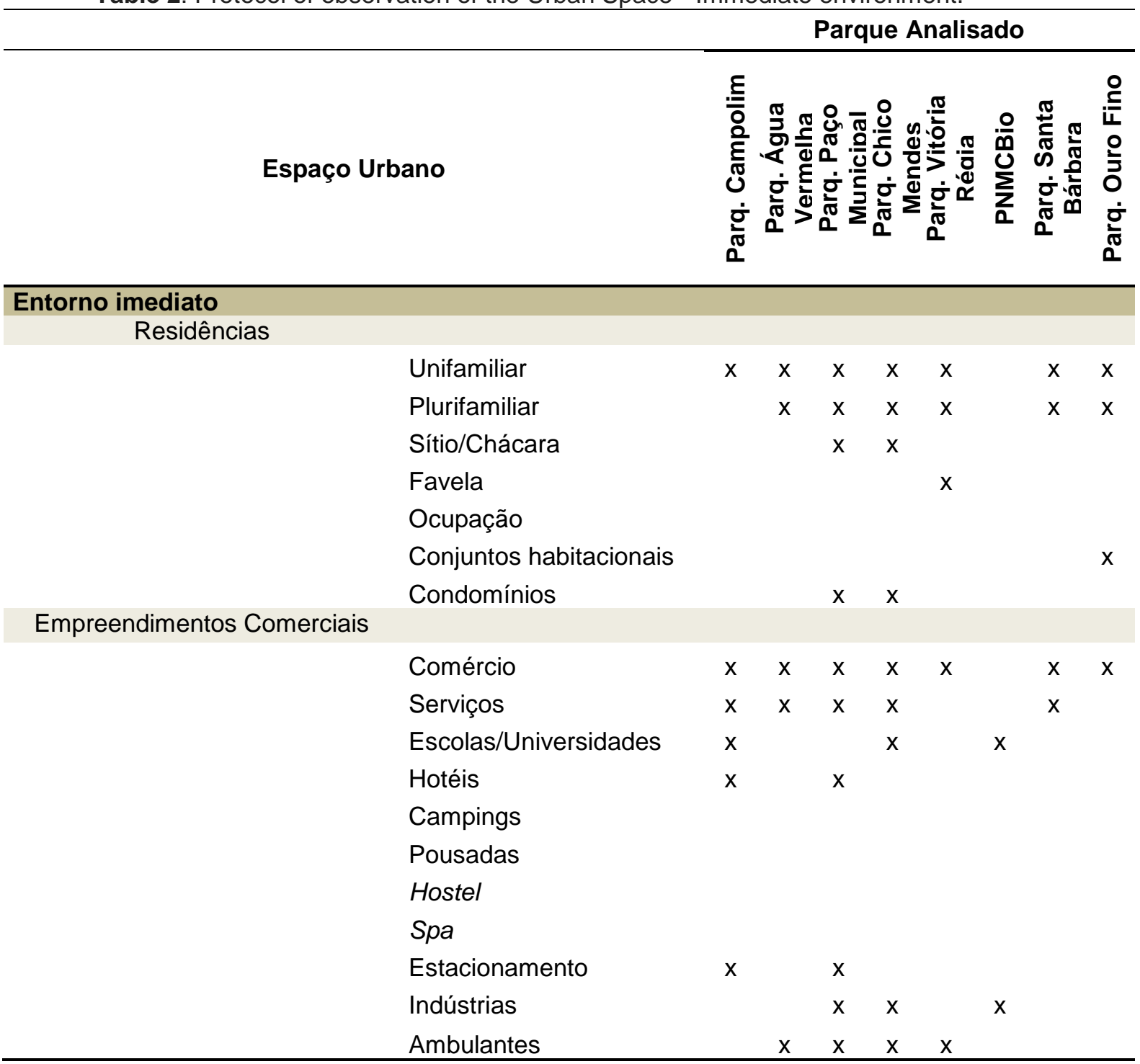

Os parques analisados estão inseridos dentro do espaço urbano e de forma geral, próximo às residências. Somente o PNMCBio é afastado da região urbanizada, localizado na zona industrial e próximo ao parque tecnológico. O Parque Vitória Régia na zona norte, tem ao seu redor regiões que passam por favelamento ao contrário do Parque Chico Mendes, na zona oeste, que abrange, em que seu entorno, um processo de construção de condomínios de casas e prédios, com a venda destes empreendimentos voltados para o apelo e temática do refúgio em meio a natureza.

Com relação aos empreendimentos comerciais, o destaque é para o Parque Campolim, zona sul, que apresenta oferta de instituições do setor de serviços, notadamente, o maior número de lanchonetes, restaurantes e 
escolas ao redor de parques. Nos parques em que não há oferta de serviços de Alimentos e Bebidas, os ambulantes são frequentes e mais numerosos, o que explicita uma situação de demanda reprimida e compreensão limitada a respeito do comportamento e das demandas de usuários destas áreas.

Além da análise do entorno, também foram realizadas análises em relação à infraestrutura urbana e aos equipamentos disponíveis, com atenção especial ao mobiliário urbano, acessibilidade e oferta de água, visando a compreensão ampla dos elementos implicados no acesso e uso destes parques (Tabela 3).

Tabela 3: Protocolo de observação do Espaço Urbano - Equipamentos Urbanos.

Table 3: Protocol of observation of Urban Space - Urban Equipment.

\section{Parque Analisado}

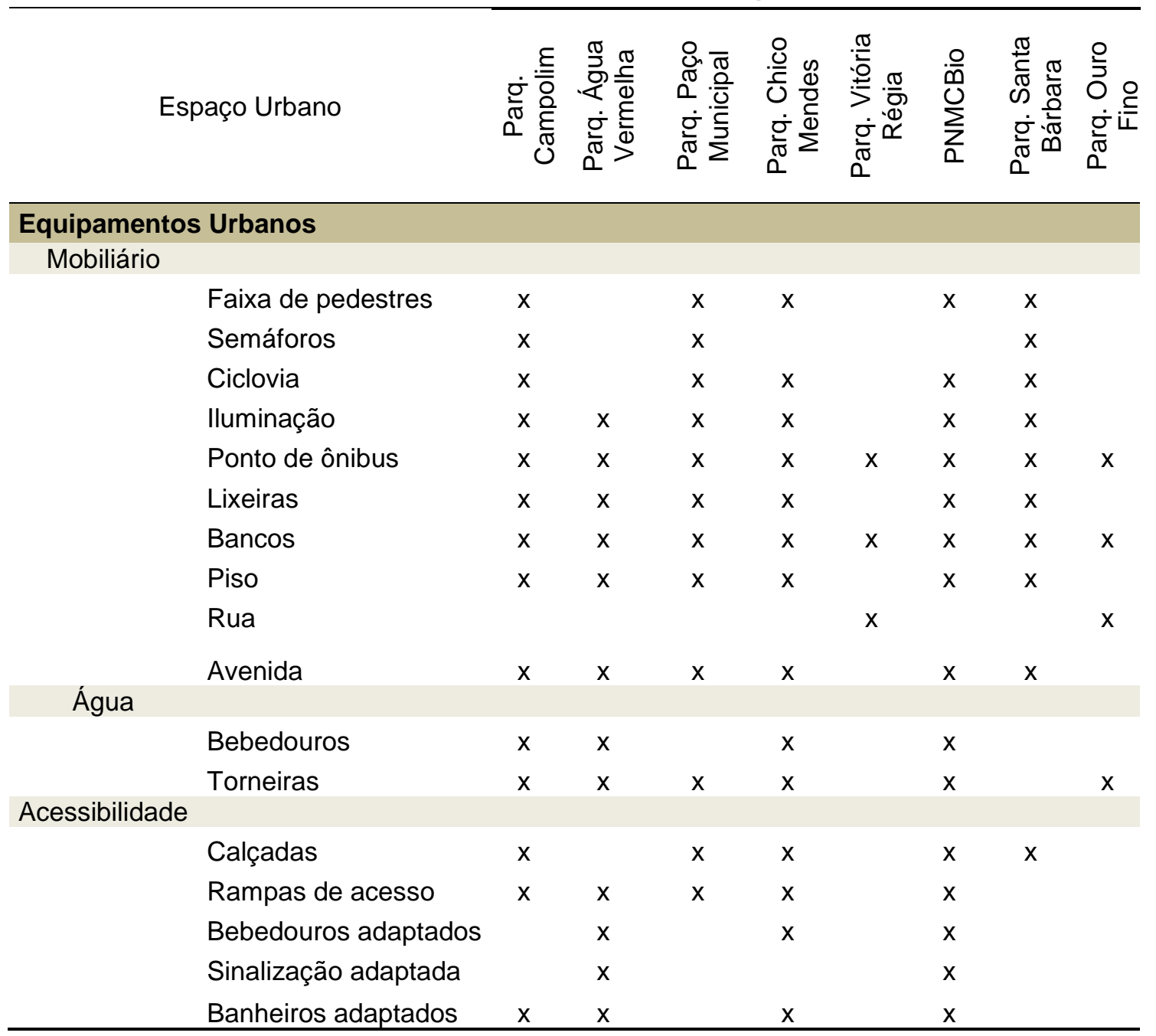

Em geral, estes espaços possuem boa ofertada de equipamentos urbanos. Próximos às avenidas de grande fluxo, somente o Parque do Ouro Fino, na zona oeste e Parque do Vitória Régia, na zona norte, estão localizados ao longo de ruas e são os que possuem a menor concentração de mobiliário urbano, como semáforos, ciclovias, lixeiras e piso. 
Outro fator relevante é o acesso à água, que não é considerada questão percebida como essencial no uso de parques e, talvez, a incompreensão do que seja uso social de áreas verdes urbanas, tendo em vista que os parques do Vitória Régia, Ouro Fino e do Paço Municipal não possuem bebedouros.

Ademais, observando-se a fundamental inclusão de pessoas com deficiência, nos espaços coletivos e públicos nas áreas urbanas e, especificamente em áreas de parques, verifica-se que a acessibilidade não é facilitada em todos os parques analisados. Os parques da Água Vermelha, zona sul e PNMCBio, zona norte são os mais equipados para receber este público, pois possuem calçadas rebaixadas, ruas guiadas, brinquedos adaptados e informações aos visitantes em braile. Em contrapartida, parques como Ouro Fino e Vitória Régia não tem nenhum equipamento que facilite a acessibilidade de pessoas com deficiência.

Inseridos no contexto das cidades, os parques funcionam como conexões de ruas e avenidas, reunindo serviços e comércios em sua vizinhança e, fundamentalmente, do ponto de vista da vida social, são imperiosos para o convívio em sociedade, para o encontro com a natureza e todos os desdobramentos sociopolíticos e culturais positivos das atividades experiências. Neste sentido a Tabela 4 apresenta os equipamentos destes espaços destinados a atividades de lazer.

Tabela 4: Protocolo de observação do Espaço Urbano - Equipamentos/Atividades de lazer.

Table 4: Protocol of observation of the Urban Space - Equipment / Leisure activities.

Parque Analisado

\begin{tabular}{|c|c|c|c|c|c|c|c|c|}
\hline Espaço Urbano & 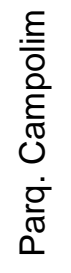 & 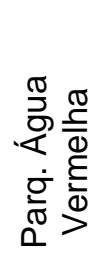 & 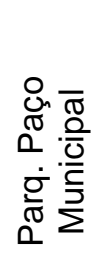 & 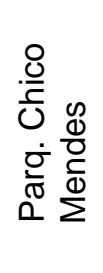 & 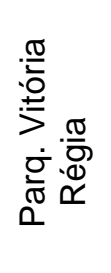 & $\sum_{\substack{0 \\
0}}^{\frac{0}{0}}$ & 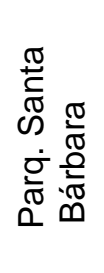 & 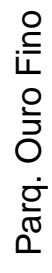 \\
\hline \multicolumn{9}{|c|}{ Equipamentos/Atividades de lazer } \\
\hline Playground & & $x$ & $x$ & $x$ & & $x$ & & $x$ \\
\hline Academia ao ar livre & $x$ & & & & $\mathrm{x}$ & & $\mathrm{x}$ & \\
\hline Pista Freestyle & & & & & & & $x$ & \\
\hline Pista caminhada & $x$ & & $x$ & & & & $x$ & \\
\hline Trilhas & & $x$ & & $x$ & & $x$ & & $x$ \\
\hline Quiosques & & $x$ & & $x$ & & & & \\
\hline Teatros & & & $x$ & & & & & \\
\hline \multicolumn{9}{|l|}{ Museus } \\
\hline Tendas multiuso & $x$ & & & & & $x$ & & $\mathrm{x}$ \\
\hline Espaços de convivência & & & & & & $x$ & & \\
\hline Lagos & & $x$ & $x$ & $x$ & & & & \\
\hline Palcos & & $x$ & & & & & & \\
\hline Campo & & & & & $x$ & & & \\
\hline
\end{tabular}


Pode-se observar que os 4 parques abertos analisados Parque Campolim (Sul), Parque do Paço Municipal (Leste), Parque Santa Barbara (Oeste) e Parque Vitória Régia (Norte) possuem pista de caminhada, campos de futebol e academia ao ar livre, assim contemplando o conteúdo cultural físico esportivo do lazer, características que lhe conferem destaque como equipamento específico de função esportiva. Outro ponto de destaque nestes equipamentos são os fragmentos de áreas verdes que passaram por um processo de tratamento paisagístico, o que compreende cuidados de conservação, estéticos e estruturais com a área, como por exemplo, corte do gramado, poda das árvores, arborização e manutenção das calçadas.

Os Parques Chico Mendes (Leste), Ouro Fino (Oeste), da Água Vermelha (Sul) e PNM - Corredores Da Biodiversidade (Norte), ou seja, os parques fechados analisados, possuem maior cobertura florestal, além de trilhas, quiosques, espaços de convivência, brinquedos e áreas para atividades de recreação e educação, cumprindo a função para a qual foram criados, tanto do ponto de vista da conservação, quanto do lazer e da recreação.

Entre todos os parques analisados somente estes (Chico Mendes, Ouro Fino, Água Vermelha e Corredores da Biodiversidade) possuem trilhas, embora os visitantes não tenham apontado o seu uso e teçam comentários sobre a má conservação - que parecem evidenciar uma concepção préconcebida, ao invés de uma leitura analítica real de sua situação, tendo em vista que também apontam a ausência de divulgação e informações sobre este equipamento. No caso específico do PNM Corredores da Biodiversidade, na zona norte, que contém três trilhas bem equipadas e estruturadas com níveis de dificuldades diferentes, verifica-se que pesa negativamente o fato de não funcionar aos domingos, sendo utilizado em maior número por estudantes, durante a semana.

Ademais, foi observado, em campo, que os parques do Paço e Chico Mendes possuem brinquedos interditados por questões de segurança aos usuários, situação que impõe, no curto prazo, restrições ao uso do público infantil e que, no longo prazo, pode implicar o desestímulo ao uso de espaços públicos e parques urbanos por esse público e seus familiares.

De maneira geral, os parques abrigam atividades de lazer vinculadas aos conteúdos culturais: social (a exemplo do encontro de grupos de caminhada e de grupos religiosos); artístico (apresentação de grupos de teatro, danças, shows musicais, grupos de pintura etc.); intelectual (contação de histórias e usuários realizando leituras). Há, também, os jogadores do game virtual Pokémon Go, concentrados em diversos grupos nos parques Campolim e Parque do Paço; os E-players aproveitam os espaços verdes, com terra e alagados para "caçarem Pokémon".

A partir da análise física e das práticas que ocorrem nestes espaços, é possível caracterizar os parques urbanos como equipamentos específicos de lazer (Tabela 5), todos estes oferecendo suporte para práticas de tempo disponível vinculadas a mais de um conteúdo cultural do lazer (DUMAZEDIR, 1980, BACAL, 1984, CAMARGO, 1986, SCHWARTZ, 2003). 
Tabela 5: Protocolo de observação do Espaço Urbano - Interesses Culturais do Lazer.

Table 5: Protocol of observation of the Urban Space - Cultural Interest of Leisure.

Parque Analisado

\begin{tabular}{|c|c|c|c|c|c|c|c|c|}
\hline Espaço Urbano & 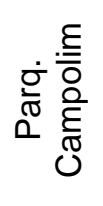 & 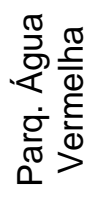 & 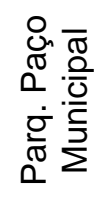 & 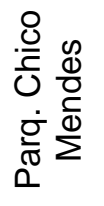 & 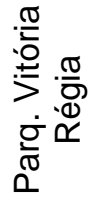 & 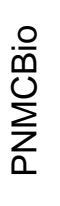 & 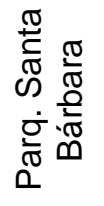 & 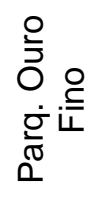 \\
\hline \multicolumn{9}{|c|}{ Interesses Culturais do Lazer } \\
\hline Artístico & $x$ & $x$ & & & & & & \\
\hline Esportivo & $x$ & & $\mathrm{x}$ & & $\mathrm{x}$ & & $\mathrm{x}$ & \\
\hline Intelectual & $x$ & $x$ & & $\mathrm{x}$ & & $\mathrm{x}$ & $x$ & \\
\hline Manual & $x$ & & & & & & & \\
\hline Social & $x$ & $x$ & $x$ & $\mathrm{x}$ & $\mathrm{x}$ & & & $\mathrm{x}$ \\
\hline Turismo & $x$ & $x$ & $x$ & & & $\mathrm{x}$ & & $x$ \\
\hline Virtual & $\mathrm{x}$ & & $\mathrm{x}$ & & & & & \\
\hline
\end{tabular}

É no tempo disponível e "livre" das obrigações que o indivíduo encontra uma maior liberdade para usufruir destes espaços e equipamentos, a fim de se recriar, buscar diversão, descanso, contemplação e desenvolvimento. É, portanto, nestes momentos, que as políticas públicas de lazer, meio ambiente e animação sociocultural podem ser inseridas e estimular transformações positivas não apenas da vida social e dos arranjos de relacionamentos sociais, como também das cidades.

Verificou-se que as visitas são realizadas por indivíduos, famílias e grupos organizados, ou seja, um público bastante diverso busca nestes espaços, em contraponto à agitada e intensa vida em áreas urbanas, 0 descanso aos finais de semana, o encontro com a natureza e a calmaria em meio à cidade. Apesar destas demandas, os parques não possuem um programa de ação pública sistemática e regular que contemple a realização de atividades recreativas dirigidas, com a participação de profissionais formados para atender as demandas da população e, objetivamente, contribuir para a fruição da vida com qualidade e para a oferta de espaços e serviços que contribuam para uma ampla e crescente qualidade de vida urbana.

Dos oito parques visitados, durante o desenvolvimento da pesquisa, apenas o parque Campolim contava com a realização de uma programação de atividades recreativas, realizada em parte pela entidade social Pintura Solidária, musical com o Rock Sinfônico, patrocinado pela CCR Via Oeste, com apoio da Secretaria de Cultura em um domingo. É forçoso afirmar que a maioria dos eventos e atividades culturais, como shows e apresentações teatrais, está concentrada no Parque Campolim.

Nos demais parques não há qualquer ação pública sendo realizada, isto quando, infelizmente, como é o caso do PNMCBio, os portões são encontrados fechados, em dia de funcionamento. A justificativa operacional apresentada para este entrave é de que há dois voluntários que cuidam de 
todo o parque e quando estes não conseguem/podem estar presentes, não há outros responsáveis do próprio municipal.

Acontecimentos recentes, observados no Parque Campolim, explicitam as contradições vividas, contemporaneamente, na vida social e, consequentemente, na fruição do lazer pela sociedade; o espaço de lazer converte-se em lócus para atividades de caráter transgressor e contestador da desigualdade socioeconômica, de acesso e uso de espaços públicos, bem como de uma suposta "disciplina" de uso dos espaços urbanos e/ou seu tratamento como "palco".

Acontecimentos de caráter transgressor e contestador da desigualdade socioeconômica, de acesso e uso de espaços públicos, bem como de uma suposta "disciplina" de uso dos espaços urbanos, também adotado como "palco", o Parque Campolim, pelas contradições que este enseja. Recentemente, em uma sexta-feira, no período noturno, um número grande de jovens, impedidos de circular livremente por um nobre shopping center próximo ao Parque Campolim, o elegeram como espaço para as práticas de lazer e, juntos, deslocaram-se e concentraram-se no parque. Após desentendimentos, tumultos e brigas, foi observada uma intervenção policial desproporcional à situação, em que muitas viaturas acessaram o parque e dispensaram os jovens com o uso de bombas de gás, situação que já havia acontecido em outro parque próximo ao bairro e Parque do Campolim, no Parque Kassatu Maru.

O contexto aqui delineado denota que as políticas públicas e a gestão pública destes espaços são fundamentais para suportar a demanda de uso e que tais demandas suplantam a oferta de eventos pontuais, vinculados às áreas de cultura e lazer, nestes espaços (Tabela 6).

Como infere Marcellino (1996), as políticas públicas de lazer e animação são recorrentemente substituídas por um calendário de eventos, muitas cidades brasileiras, condutas que explicitam o desconhecimento da importância social do lazer e/ou escolhas políticas distantes do cumprimento das responsabilidades e compromissos estatais relativos à garantia do direito ao lazer. Para o autor, os pacotes técnicos de atividades de lazer e recreação somente obedecem a um cronograma de atividades, que não estão contextualizadas com a realidade de cada local, situação que se desdobra na baixa adesão e participação da sociedade no "programa de eventos", bem como nas discussões de planejamento, execução e avaliação das políticas públicas de lazer. Tal situação foi verificada por Kachinski e Stoppa (2010) na cidade de Sorocaba, em estudado sobre as políticas públicas de lazer e cultura do município. 
Tabela 6: Protocolo de observação do Espaço Urbano - Gestão Pública.

Table 6: Protocol of observation of the Urban Space - Public Management.

\begin{tabular}{|c|c|c|c|c|c|c|c|c|c|}
\hline \multirow{2}{*}{\multicolumn{2}{|c|}{ Espaço Urbano }} & \multicolumn{8}{|c|}{ Parque Analisado } \\
\hline & & 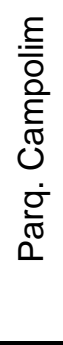 & 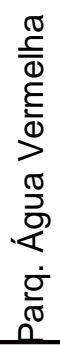 & 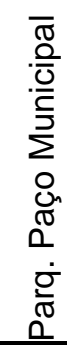 & 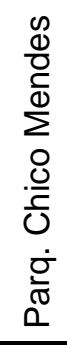 & 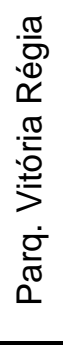 & $\begin{array}{l}\frac{0}{0} \\
\sum_{0}^{0} \\
\end{array}$ & 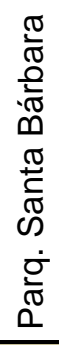 & 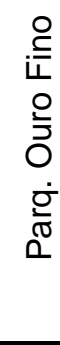 \\
\hline \multicolumn{10}{|c|}{ Gestão Pública } \\
\hline \multicolumn{10}{|l|}{ Informações } \\
\hline & Placas indicativas & & $\mathrm{x}$ & & $\mathrm{x}$ & & $\mathrm{x}$ & $\mathrm{x}$ & $\mathrm{x}$ \\
\hline & Sinalização de atividades/eventos & & & & $\mathrm{x}$ & & $\mathrm{x}$ & & \\
\hline & Material impresso/mural & & $\mathrm{x}$ & & $x$ & & $x$ & & \\
\hline \multicolumn{10}{|l|}{ Manutenção } \\
\hline & Iluminação & $\mathrm{x}$ & $\mathrm{x}$ & $\mathrm{x}$ & $\mathrm{x}$ & & & $\mathrm{x}$ & \\
\hline & Equipamentos & $x$ & $x$ & $x$ & $x$ & & $\mathrm{x}$ & $x$ & \\
\hline & Lixeiras & $x$ & $\mathrm{x}$ & $x$ & $\mathrm{x}$ & & $x$ & & \\
\hline & Paisagismo & $\mathrm{x}$ & $\mathrm{x}$ & $\mathrm{x}$ & $\mathrm{x}$ & & $\mathrm{x}$ & & \\
\hline & Limpeza & $\mathrm{x}$ & $\mathrm{x}$ & $\mathrm{x}$ & $\mathrm{x}$ & & $\mathrm{x}$ & & $\mathrm{x}$ \\
\hline \multicolumn{10}{|l|}{ Segurança } \\
\hline & Base comunitária & & & & & & & & \\
\hline & Base móvel & $x$ & & & & & & & \\
\hline & Viaturas & $\mathrm{x}$ & $\mathrm{x}$ & $\mathrm{x}$ & $\mathrm{x}$ & & & & \\
\hline & Cavalaria & $\mathrm{x}$ & & & & & & & \\
\hline \multicolumn{10}{|l|}{ Serviços } \\
\hline & Alimentação & & & & & & & & \\
\hline & Banheiros & $\mathrm{x}$ & $x$ & & $\mathrm{x}$ & & $\mathrm{x}$ & & \\
\hline & Programação sociocultural & $\mathrm{x}$ & $\mathrm{x}$ & & & & $\mathrm{x}$ & & \\
\hline & Internet & $x$ & & $\mathrm{x}$ & & & & & \\
\hline \multicolumn{10}{|l|}{ Parcerias/terceiros } \\
\hline & ONGs/entidades civis/voluntários & $\mathrm{x}$ & & & $\mathrm{x}$ & & $\mathrm{x}$ & & \\
\hline & Equipamentos/atividades & $\mathrm{x}$ & & & $\mathrm{x}$ & & & & \\
\hline \multicolumn{10}{|c|}{ Legislação/Programas } \\
\hline & Programa de Uso Público & & & & & & $\mathrm{x}$ & & \\
\hline & Lei municipal & $\mathrm{x}$ & $x$ & $\mathrm{x}$ & $\mathrm{x}$ & & $x$ & $x$ & $x$ \\
\hline & Conselho & & & & & & $x$ & & \\
\hline & Associação de usuários/moradores & & & & & & & & \\
\hline
\end{tabular}

O enfrentamento desta problemática supõe, inevitavelmente, o diálogo constante entre o poder público e a sociedade, evitando o afastamento das comunidades frente ao planejamento das ações e políticas públicas de lazer e meio ambiente. Portanto, políticas públicas que tenham como objeto o uso público demandam, além de ações públicas de planejamento participativo, com a respectiva formatação de um ou mais programas, o delineamento de um espaço político plural efetivo para a tomada de decisões, 
democraticamente, em atenção ao atendimento das demandas sociais, voltadas à garantia da qualidade de vida urbana, de direitos sociais e ao fortalecimento, indireto, da democracia.

No que diz respeito à definição de um Programa de Uso Público, Pacheco e Raimundo (2014) detalham elementos que devem ser contemplados: aspectos culturais, atividades artísticas, apresentações, festividades e oficinas que contemplem a todos.

Com espaços para as práticas lúdico-recreativas diversas, além das esportivas e corporais, os parques e Programas de Uso Público podem e devem fomentar a fruição de práticas manuais e intelectuais, sociais, bem como, contar com programas que tenham características da animação socioambiental, ou seja, podem contar com a presença de mediadores, educadores capazes de realizar intervenções socioeducativas no âmbito do meio ambiente, de modo a minimizar as barreiras inter e intraclasses sociais, presentes na vida cotidiana dos cidadãos e na apropriação destes espaços. Iniciativas nesta linha, certamente, contribuiriam para a conformação de novos espaços de encontro, de lazer, mais condizentes com as transformações, realidades contemporâneas e perspectivas positivas futuras para a vida humana.

Sorocaba conta com uma Secretaria exclusiva para o meio ambiente e, segundo dados apresentados no portal de transparência da cidade, em 2016, foram gastos nesta área mais de 13 milhões de reais. Com relação a Planos de Manejo e Programas de Uso Público, dos 33 Parques, apenas o PNMCBio possui um Plano de Manejo, que contempla um Programa de Uso Público (criado pelo Decreto Municipal 16.408, de 23 de dezembro de 2008) elaborado e submetido à consulta pública para sugestões da população, por meio de audiência pública. No entanto, a única área que possui um Plano de Manejo e um Programa de Uso Público, atualmente, encontra-se fechada a visitação aos finais de semana.

Por outro lado, Sorocaba é vista como uma cidade atuante em relação as suas políticas públicas de criação de parques, natureza e meio ambiente. No texto do documento do Plano Diretor, aprovado em Lei no 11.022 (16 de dezembro de 2014), a expansão dos parques aparece como um dos objetivos, parques estes, em alguns casos, considerados para Usos Especiais e incluídos na categoria de Macrozona de Conservação Ambiental.

As políticas públicas de criação de parques na cidade se intensificaram a partir da criação da Secretaria de Meio Ambiente de Sorocaba, em 2008, (MANFREDINI; GUANDIQUE; ROSA, 2015). A partir deste ano, as Unidades de Conservação (BRASIL, 2000) foram instauradas e diversas áreas objeto de restauração foram transformadas em parques urbanos ou parques naturais municipais.

Acrescenta-se às problemáticas aqui analisadas o fato de que alguns parques da cidade que foram criados em um primeiro momento para atender demandas de caráter urbanístico, a fim de organizar os espaços ocupados pela população. Exemplo destes processos urbanísticos vem ocorrendo desde 2017, em uma área ocupada no bairro Vila Barão, zona norte da 
cidade, ação que segundo a Prefeitura de Sorocaba compreende a remoção de 150 famílias com baixa renda e poder aquisitivo, de uma localidade próxima ao Aeroporto Estadual Bertram Luiz Leupolz, em virtude da ampliação de suas atividades e área, espaço que futuramente será convertido em parque.

Segundo Burgos (2015), outros parques da cidade, em um primeiro momento, também foram criados em função de demandas urbanas, como para conter situações de alagamento, ao exemplo do Parque Campolim, criado em 1999, com a função e denominação de bacia de contenção do Campolim. O Parque da Água Vermelha e o Parque das Águas também foram criados para conter processos de inundação.

Neste contexto, a cidade possui mais de 33 parques e em 2013 a cidade foi avaliada em primeiro lugar no ranking do Programa Município Verde e Azul, posição de destaque mantida em 2016, seguindo entre as 10 melhores pontuações. Um indicador verificado no "Município Verde e Azul" refere-se, diretamente, à criação de um programa de educação ambiental (EA), que pode ter como lócus de desenvolvimento significativo os parques urbanos e naturais.

Além da Secretaria do Meio Ambiente, que possui competência e responsabilidade diretamente relacionada aos parques urbanos e naturais há outras secretarias, dedicadas à implementação de agendas políticas para os esportes, lazer, cultura e educação que, se atuassem em parceria, poderiam somar esforços na reversão de diversos problemas urbanos e na transformação efetiva de espaços urbanos.

As reflexões realizadas pela pesquisa de campo apontam a importância do papel desempenhado pelas políticas públicas e pelos Programas de Uso Público, que compreendem a estreita interface entre as questões e temas do meio ambiente, da cultura e do lazer e as múltiplas possibilidades de práticas a estes vinculadas, nos parques urbanos e naturais de Sorocaba.

\section{Considerações Finais}

De maneira geral os parques estão distribuídos em toda a cidade, não caracterizando desigualdades na oferta de parques a população. Atualmente, as regiões leste e norte, possuem o maior número de parques e a concentração destes não está relacionada às características de renda das regiões.

Em contrapartida, os parques mais bem avaliados, nos quesitos infraestrutura, manutenção e segurança estão nas regiões onde a população apresenta maior renda; são também os que recebem um número maior de visitantes e são mais frequentemente visitados.

Os Parques Campolim, Água Vermelha, ambos na zonal sul e Chico Mendes, zona leste que recebem visitantes de todas as zonas de Sorocaba. Estes parques são mais bem dotados de equipamentos urbanos e de lazer, contam com cuidados paisagísticos, mais segurança e intervenções com 
atividades desenvolvidas por instituições do setor público e instituições privadas do terceiro setor $e$, por isso, provocam o deslocamento de residentes/usuários na área urbana; muitos acabam saindo de regiões mais distantes para frequentar estes parques.

Há, em Sorocaba, parques em piores condições de conservação e de oferta de infraestrutura e equipamentos, que acabam sendo subutilizados, em detrimento de parques localizados em áreas enobrecidas e valorizadas pelo mercado imobiliário, com maior concentração de renda no entorno e que, consequentemente, recebem mais atenção por parte do poder público e da iniciativa privada, que se desdobra em ações frequentes de conservação e na oferta, regular e diversificada, de programação de lazer, cultura e animação, resultando em maior frequência de utilização por residentes e visitantes. Outro aspecto relevante é que apenas o Parque da Água Vermelha e o PNMCBio contam com uma melhor infraestrutura para receber pessoas com deficiência, com placas em braile e caminhos sinalizados. Entretanto, constatou-se que o uso realizado por pessoas com deficiência é pequeno.

Atualmente, os parques não contam com a devida atenção, em seus aspectos de conservação, paisagismo e de infraestrutura com destaque para o Parque Vitória Régia, Parque do Ouro Fino, Parque Santa Bárbara e Parque do Paço. Estes parques urbanos mais periféricos (exceto Parque do Paço), carecem de equipamentos de recreação e atividades para crianças, assim como para os adultos. Os Parques Vitória Régia, zona norte e Santa Bárbara, zona oeste, ambos periféricos, não possuem maiores cuidados na manutenção, segurança e infraestrutura.

A ocupação e os usos destes espaços urbanos são diversos e apesar de observado mais de um conteúdo cultural do lazer, os parques urbanos possuem características que favorecem o estímulo do conteúdo cultural físico esportivo, evidenciando aparelhos de ginástica, pistas de caminhada e também campos de futebol. A despeito da demonstração de uma historicamente recente noção de prática de lazer em parques, voltado para promoção da saúde, é importante destacar que estes parques urbanos, são fundamentais para encontros entre pessoas, da musicalidade, brincadeiras e convívios e contestações; o parque Campolim tem sido palco de manifestações políticas de diversos grupos sociais, agregando outras funcionalidades a este parque.

Portanto, mesmo que a literatura entenda que os parques urbanos tem maior relevância como espaços livres de uso público e interesse social, para uso recreativo e de lazer, e os parques naturais como importantes para conservação, é possível assumir que os parques naturais compreendem também o lócus para atividades recreativas e culturais, a fim de despertar os sentimentos e o prazer pelo contato com a natureza, fazendo com que indivíduos possam desenvolver um comportamento em prol da conservação e salvaguarda do ambiente.

Por outro lado, a sociedade como um todo, por meio de ações individuais e coletivas, em conjunto com governo, entidades privadas e 0 terceiro setor, devem provocar questionamentos acerca da ordem social estabelecida, contribuindo para a superação do status quo e para a 
construção de uma cidade mais justa e com mais consciência a respeito da conservação da natureza.

Assim, além da apropriação e uso dos parques, é preciso estimular que usuários e cidadãos se apoderem dos espaços públicos existentes, também políticos, e criem novas perspectivas e discussões sobre a verdadeira importância e relevância da conservação natureza em meio ao espaço urbano.

A elaboração, implementação e gestão de novas ações e políticas públicas, a partir das perspectivas da animação sociocultural, que tem como objetivo a transformação de valores e de comportamentos que, efetivamente, possam ser convertidos em condutas mais responsáveis e ambientalmente sustentáveis nos parques urbanos de Sorocaba, ainda é algo fundamental para a definição de um programa de Uso Público. Portanto, deve-se levar em consideração os elementos e as dinâmicas que conformam e conferem segurança aos espaços públicos.

Embora longe de concluir o assunto, entende-se que o estudo pode colaborar para o entendimento de como o sorocabano se apropria e usa os parques, suas relações com a natureza e os anseios por transformações urbanas positivas. Outrossim, que as reflexões aqui compartilhadas subsidiam novas reflexões acerca das características das práticas de fruição do lazer, da recreação, da natureza e da cultura, por parte da população, consubstanciando novas ações por parte das instituições do setor público e outras instituições de caráter privado, com a respectiva redefinição de seu compromisso com a instauração de uma sociedade mais justa, participativa e sustentável.

Registra-se, por fim, que uma política de expansão da criação de parques urbanos e naturais, que vem ocorrendo na última década, na cidade de Sorocaba, deve vir acompanhada de uma política pública e de programas de uso público destes espaços e de seus equipamentos constitutivos.

\section{Referências}

BACAL, S. S. Pressupostos do comportamento turístico: influências psicológicas, sócio-culturais e econômicas. São Paulo: ECA/USP, 1984, 251 p. (Tese de Doutorado).

BURGOS, R. Espaços públicos e o direito à cidade: Contribuições teóricoconceituais a partir de estudos sobre o uso de parques urbanos em contextos de segregação espacial nas cidades de São Paulo e Sorocaba. Revista Cidades, v. 12 n. 20, 2015.

BRASIL. Senado Federal. Constituição da República Federativa do Brasil. Brasília: Centro gráfico - Senado Federal, 1988.

BRASIL. Lei 9985, de 2000 - SNUC - Sistema Nacional de Unidades de Conservação da Natureza. 
BRASIL: Instituto Brasileiro de Geografia e Estatística - IBGE. Estatísticas do século $\mathbf{X X}$ em: https://ww2.ibge.gov.br/home/presidencia/noticias/29092003 estatisticasecxx html.shtm> acessado em 30 de janeiro de 2018 às $15 \mathrm{~h} 40$.

CAMARGO, H.L. Uma pré-história do turismo no Brasil: recreações aristocráticas e lazeres burgueses (1808-1850). São Paulo: Aleph, 2007.

CAVALCANTI, C. Sustentabilidade: mantra ou escolha moral? Uma abordagem ecológico-econômica. Universidade de São Paulo. Estudos Avançados, v. 26, n. 74, 2012.

DANTAS, M.K. Análise da gestão ambiental no Estado de São Paulo: Programa município VerdeAzul, gastos públicos e indicadores de saúde. Ribeirão Preto, 2016. 211p. Faculdade de Economia, Administração e Contabilidade - Ribeirão Preto/USP.

DUMAZEDIR, J. Valores e conteúdos culturais do lazer. São Paulo: Sesc, 1980.

GEHL, J. Cidades para pessoas: tradução Anita Di Marco - 2 ed. São Paulo: Perspectiva, 2013.

GEHL, J. SVARRE, B. How to study public life. Editora Sland Press, 2013.

GUTIERREZ G. L. Lazer e pobreza: aspectos de uma falsa questão. Conexões, v.1, n. 1, p. 28-38, 1998.

JACOBI, P.R. Educação Ambiental: o desafio da construção de um pensamento crítico, complexo e reflexivo. Educação e Pesquisa, São Paulo, v.31, n. 2, p. 233-250, maio/ago. 2005.

JACOBS, J. Morte e vida de grandes cidades. São Paulo: Editora WMF Martins Fontes, 2011. - (Coleção Cidades).

KACHINSKI, K.V.B; STOPPA, E.A. Políticas Públicas de Lazer: um estudo de caso na Secretaria Municipal de Esportes, Lazer e Recreação de São Paulo Seme. Revista Turismo \& Desenvolvimento, v. 09, p. 61-78, 2010.

LEFEBVRE, H. O direito a cidade. São Paulo: Editora Centauro, 5 ed. 2001. 3a reimpressão - 2011.

LIMA, V.; AMORIM, M. C. C. T. A importância das áreas verdes para a qualidade ambiental das cidades. Revista Formação, n.13, p. $139-165$. 2006.

LONDE, P.R; MENDES, P.C. A influência das áreas verdes na qualidade de vida urbana. Universidade Federal de Uberlândia. Revista Brasileira de Geografia Médica e Saúde, v. 10, n. 18, jun./2014.

MANFRADINI, F.N; GUANDIQUE, M.E.G; ROSA, A.H. A história ambiental de Sorocaba. Sorocaba: Unesp - Instituto de Ciência e Tecnologia - Campus Sorocaba, 2015.

MARCELLINO, N.C. Estudos do lazer: uma introdução. Campinas, SP: Autores Associados, 1996. 
MELLO, K. Análise Espacial de remanescentes florestais como subsidio para o estabelecimento de unidade de conservação. 2012. 82 f. Dissertação de Mestrado (PPGDBC) - Centro de Ciências e Tecnologias para Sustentabilidade, Universidade Federal de São Carlos - Sorocaba. Sorocaba, 2012.

MOTA, M.T. "Parques" em paisagem urbana, proposta de um sistema municipal integrando áreas verdes e áreas protegidas - estudo de caso no sudeste do Brasil. 2013. 88 f. Dissertação de Mestrado (PPGSGA) - Centro de Ciências e Tecnologias para Sustentabilidade, Universidade Federal de São Carlos - Sorocaba. Sorocaba, 2013.

MUNHOZ, V.C.C. O lazer como direito social na prefeitura de Belo Horizonte. In: ISAYAMA, H.F; LINHALES, M.A. (Org.). Avaliação de políticas e políticas de avaliação: questões para o esporte e o lazer. Belo Horizonte: UFMG, 2008, p. 59- 100.

PACHECO, R.T.B; RAIMUNDO, S. Parques urbanos e campos dos estudos do lazer: propostas para uma agenda de pesquisa. Rev. Brasileira de Estudos do Lazer. Belo Horizonte, v. 1, n. 3, p. 43-66, set./dez. 2014. Dossiê Lazer e Meio Ambiente.

PAULA, I.F.M.; FERREIRA, C.C.M. Análise dos espaços de uso público da cidade de Juiz de Fora (MG) com base no conceito de áreas verdes. Caminhos de Geografia, v. 15, n. 49 p. 160 - 174, Mar /2014. Uberlândia 2014.

PRIORE, M.D. Histórias da gente brasileira. Vol. 1: Colônia. Ed.: LeYa. São Paulo, 2016.

PLANO MUNICIPAL DE MATA ATLÂNTICA. Plano Municipal de conservação e Recuperação de Mata Atlântica. Sorocaba, 2014. 154 p. Disponível em: <https://www.sosma.org.br/wp-content/uploads/2014/04/pmma -sorocaba-bx.pdf> Acesso em: 08 maios 2016.

REIS, R.R.G. Estimação do preço implícito de amenidades urbanas no município de Sorocaba. 2015. 74 f. Dissertação de Mestrado (Mestrado em Economia Aplicada) - Centro de Ciências e Tecnologias para Sustentabilidade, Universidade Federal de São Carlos, Sorocaba, 2015.

RODRIGUES, A.M. Problemática ambiental: agenda política, espaço, território e classes sociais. Publicado: Boletim Paulista de Geografia, São Paulo, no 83, dez. 2005 p. 91-110.

ROLNIK, R. O lazer humaniza o espaço urbano. In: SESC SP. (Org.). Lazer numa sociedade globalizada. São Paulo: SESC S.Paulo/World Leisure, 2000.

SCHWARTZ, G.M. O conteúdo virtual: contemporizando Dumazedier. Licere, Belo Horizonte, v.2, n.6, p.23-31, 2003.

STOPPA, E.A. Tá ligado manoll: o hip-hop como lazer e busca da cidadania. 2005. 143f. Tese (Doutorado em Educação Física) -Faculdade de Educação Física. Universidade Estadual de Campinas, Campinas, 2005. 
VILARTA, R.; GONÇALVES, A. Qualidade de vida: concepções básicas voltadas à saúde. In: GONÇALVES, A.; VILARTA, R. (Org.). Atividade Física e Qualidade de vida: explorando teoria e prática. 1. ed. Barueri: Manole, 2004, v. 1, p. 27-62.

\section{Notas:}

1 Os autores em construção coletiva com os alunos da disciplina Uso Público em Parques Urbanos da EACH/USP criaram um roteiro de observação de parques urbanos.

2 Sub-Região 1: Alambari, Boituva, Capela do Alto, Cerquilho, Cesário Lange, Jumirim, Sarapuí, Tatuí, Tietê e Itapetininga, município que foi incorporado à região após a sua institucionalização; Sub-Região 2: Alumínio, Araçariguama, Ibiúna, Itu, Mairinque, Porto Feliz, Salto e São Roque; Sub-Região 3: Araçoiaba da Serra, Iperó, Piedade, Pilar do Sul, Salto de Pirapora, São Miguel Arcanjo, Sorocaba, Tapiraí e Votorantim

Kleber Vinícius Barros Kachinsk: Universidade Federal de São Carlos, Sorocaba, SP, Brasil.

E-mail: kleber.kachinski@gmail.com

Link para o currículo Lattes: http://lattes.cnpq.br/5525206301332584

Maria Helena Mattos Barbosa dos Santos: Universidade Federal de São Carlos, Sorocaba, SP, Brasil.

E-mail: lena_mbsantos@yahoo.com.br

Link para o currículo Lattes: http://lattes.cnpq.br/3419477918842537

Eliana Cardoso-Leite: Universidade Federal de São Carlos, Sorocaba, SP, Brasil.

E-mail: cardosoleite@yahoo.com.br

Link para o currículo Lattes: http://lattes.cnpq.br/2186623269243747

Data de submissão: 14 de março de 2018

Data de recebimento de correções: 23 de julho de 2018

Data do aceite: 23 de julho de 2018

Avaliado anonimamente 